\title{
秎 \\ POSSIBILIDADES E OBSTÁCULOS NA GESTÃO DE PERFIS EM REDES SOCIAIS PELAS ASSEMBLEIAS LEGISLATIVAS DA REGIÃO SUDESTE DO BRASIL
}

\author{
POSSIBILITIES AND OBSTACLES IN THE MANAGEMENT OF SOCIAL MEDIA \\ PROFILES BY LEGISLATIVE ASSEMBLIES IN THE SOUTHEAST REGION OF \\ BRAZIL
}

\author{
POSIBILIDADES Y OBSTÁCULOS EN LA GESTIÓN DE PERFILES EN REDES \\ SOCIALES POR ASAMBLEAS LEGISLATIVAS EN LA REGIÓN SURESTE DE \\ BRASIL
}

Cristiane Brum Bernardes ${ }^{1}$

\begin{abstract}
Resumo: Por meio de entrevistas em profundidade, o estudo ana lisa como os conceitos de e-transparência e e-participação são mobiliza dos pelas equipes que gerenciam os perfis institucionais nas redes sociais das quatro assembleias legislativas da Região Sudeste do Brasil. A partir dos depoimentos dos gestores dos processos de digitalização das casas legislativas, percebe-se que as possibilidades de comunicação abertas nas mídia s sociais podem contribuir para a mpliação e melhoria da relação entre parlamentares e cida dãos. Também são analisadas as dificuldades que as equipes relatam e que servem como alerta para as boas práticas na área.
\end{abstract}

Palavra-chave: Democracia Digital; Parlamento Digital; Assembleias Legislativas; Poder Legislativo; Parlamentos e Internet.

\begin{abstract}
Through in-depth interviews, the study analyzes how the concepts of e-transparency and eparticipation are mobilized by the teams that manage the institutional social media profiles of the four legislative assemblies of the Southeast Region of Brazil. From the statements made by the managers of the processes of digitization of legislative houses, it is perceived that the possibilities of communication opened by social media can contribute to the expansion and improvement of the relationship between parliamentarians and citizens. It is also analyzed how the difficulties reported by the teams serve as a warning for good practices in the area.
\end{abstract}

Keywords: Digital Democracy; Digital Parliament; Legislative Assemblies; Legislatures; Pa rliaments \& Internet.

Resumen: A través de entrevistas en profundidad, elestudio ana liza cómo los conceptos de e-transparencia y participación electrónica son movilizados por los equipos que gestionan los perfiles institucionales en las redes sociales de las cuatro asambleas legislativas de la Región Sureste de Brasil. A partir de las declaraciones de los gestores de los procesos de digitalización de las cámaras legislativas, se percibe que las posibilidades de comunicación abierta en las redes sociales pueden contribuir a la expansión y mejora de la relación entre parlamentarios y ciudadanos. También se analizan las dificultades que los equipos reportan y que sirven como advertencia de buenas prácticas en lo tema.

Palabras clave: Democracia Digital; Parlamento Digital; Asambleas Legislativas; Poder Legislativo; Parlamentos y Internet.

\footnotetext{
${ }^{1}$ Docente e pesquisadora do Mestrado em Poder Legislativo do CEFOR. Doutora em Ciência Política (IESP/UERJ). Mestra em Comunicação e Informação (UFRGS). Integrante do Instituto Nacional em Ciência e Tecnologia em Democracia Digital (INCT-DD). Pesquisadora associada do Centro para Engajamento Público da Universidade de Leeds (Reino Unido).
} 


\section{Introdução}

A relação entre Democracia e Internet, ou tecnologias digitais, tem sido amplamente discutida em vários campos do conhecimento há, pelo menos, 20 anos. Como ressalta Gomes (2018), se há uma crescente digitalização da vida e uma respectiva ampliação das funções cumpridas pelos ambientes digitais, incluindo aí a mobilidade e a hiperconexão como tendências centrais da última década, não faria sentido pensar que o mundo da política também não seria afetado por esses processos. Como as demais tarefas sociais, também as atividades pertinentes à vida pública estão sendo realizadas por meio do mundo digital, em velocidade crescente. Se a internet, portanto, moveu-se da era da informação para a era da comunicação e produção de redes (JENSEN, 2013), faz sentido que o foco deste estudo esteja nas estratégias de uso tecnológico que parlamentos subnacionais brasileiros utilizam em relação aos chamados "sites de redes sociais" (BOYD \& ELLISON, 2008)2 .

Nesse contexto social, o termo Democracia Digital foi definido de forma bastante ampla por Simon et al. como "a prática da democracia usando ferramentas e tecnologias digitais" (2017, p.11). Em sentido similar, Gomes aponta que a expressão designa “(...) o conjunto de recursos, ferramentas, projetos, experimentos, experiências e iniciativas em que se usam tecnologias para produzir mais democracia e melhores democracias" (SIMONET AL., 2018, s/p).

Entre os pesquisadores dedicados ao tema, Margetts (2013) lembra a influência das tecnologias digitais sobre os processos eleitorais e o papel dos partidos no panorama contemporâneo, além do uso que movimentos sociais, grupos de interesse, governos e parlamentos têm feito das ferramentas à disposição. A autora destaca que os parlamentos, apesar de mais lentos na adoção da tecnologia, já são alvo de diversas transformações provocadas por ela, tais como o aumento da transparência e a possibilidade de participação popular nas decisões (MARGETTS, 2013,p.425). ${ }^{3}$

Se as pesquisas contemporâneas versam, em boa medida, sobre a e-transparência e a eparticipação, conforme constata Gomes (2018), é interessante pensar como essas questões estão sendo trabalhadas internamente pelas instituições que conformam os regimes democráticos representativos: os Parlamentos. O objetivo deste artigo, portanto, é compreender como essas duas dimensões se articulam na prática de legislaturas subnacionais brasileiras, especificamente a partir do discurso dos gestores dos perfis institucionais das casas legislativas nas plataformas de mídias sociais.

Tendo em vista a variedade de estudos já conduzidos sobre as estratégias de digitalização e uso da internet pelos parlamentos nacionais (BRAGA, 2008; FARIA, 2012; BARROS et al.

\footnotetext{
${ }^{2}$ Segundo boyd e Ellison (2008), os SITES DE REDES SOCIAIS são serviços de internet que permitem aos indivíduos 1) construir um perfil público nos limites do sistema; 2) articular uma lista de outros usuários com quem querem se conectar; e 3) ver e navegar por sua lista de contatos e pela lista dos demais no sistema.

${ }^{3}$ A categorização de Sampaio et al. (2019) sobre o "valor democrático" das iniciativas de Democracia Digital parece interessante também para nossa análise. Voltaremos ao ponto mais adiante.
} 
2015; BARROS et al. 2016; MENDONÇA; PEREIRA, 2016; MITOZO, 2018), o foco aqui está nas práticas de quatro casas subnacionais localizadas na Região Sudeste: Assembleia Legislativa de Minas Gerais (ALMG), Assembleia Legislativa do Estado de São Paulo(ALESP), Assembleia Legislativa do Espírito Santo (ALES) e Assembleia Legislativa do Estado do Rio de Janeiro (ALERJ).

A comparação entre as iniciativas e estratégias de assembleias estaduais de uma mesma região do país permite avaliar se existem diferenças estaduais que justifiquem diferentes abordagens no uso das tecnologias por essas casas, ou se as diferenças se devem mais às estratégias discursivas escolhidas pelos atores políticos para lidar com a nova realidade de engajamento político digital, a partir de cenários organizacionais distintos. Ressalte-se a escassez de pesquisas sobre as dinâmicas institucionais dos legislativos estaduais ou mesmo municipais do País nas redes sociais, em que pese a possibilidade comparativa que of erecem (LUCINDA, 2016; LUCINDA \& BERTASSO 2017; JÚLIO NETO, 2019).

A escolha pela Região Sudeste se deveu ao fato de ser a região que congrega o maior contingente populacional do País, além de sustentar índices relevantes de acesso à internet. Segundo dados do $\mathrm{IBGE}^{4}$, os três estados brasileiros mais populosos estão na região: São Paulo, com 46 milhões de habitantes; Minas Gerais, com 21,2 milhões; e Rio de Janeiro, com 17,2 milhões. Espírito Santo, com apenas 4 milhões de habitantes, completa a região. Com o total de 88,4 milhões de habitantes, o Sudeste detém mais de $42 \%$ da população brasileira. Em relação ao percentual de uso de internet no Brasil, a PNAD de 2017 mostrou que, na região, 81,1\% dos domicílios utiliza internet, enquanto o índice nacional para 2017 era de 74,9\% das residências.

Os três mais populosos estados brasileiros também detêm os maiores eleitorados: São Paulo responde por 22,5\% dos eleitores, Minas Gerais por 10,6\% e Rio de Janeiro por 8,4\%. Em conjunto com o Espírito Santo, que tem 1,9\% dos eleitores brasileiros, a Região é responsável por $43,4 \%$ dos votos no país. Consequentemente, uma vez que o número de eleitos para o Legislativo é proporcional à população de cada distrito eleitoral, são eles também os detentores das maiores bancadas na Câmara dos Deputados e também dos maiores legislativos estaduais em número de parlamentares: 94 em São Paulo, 77 em Minas Gerais e 70 no Rio de Janeiro. No Espírito Santo, a assembleia é composta por 30 deputados estaduais.

A coleta de dados empíricos foi realizada entre agosto de 2018 e novembro de 2019 a partir da aplicação de entrevistas em profundidade com os gestores da comunicação digital das casas legislativas. As entrevistas com os responsáveis pela gestão dos perfis nas mídias sociais da ALMG e da Alerj foram realizadas entre agosto de 2018 e janeiro de 2019, enquanto os gestores dos perfis da ALES e da Alesp foram entrevistados em outubro de 2019.

É importante destacar que este estudo é parte de uma pesquisa mais ampla sobre as redes

\footnotetext{
${ }^{4}$ Os dados populacionais foram extraídos das projeções realizadas pelo Instituto Brasileiro de Geografia e Estatística (IBGE) disponíveis em: https://www.ibge.gov.br/apps/populacao/projecao/index.html, acessado em: 8 de nov. 2019.
} 
sociais das quatro casas legislativas mencionadas. Dessa forma, análises comparativas do conteúdo das publicações nos perfis of iciais das instituições no Facebook e no Twitter já foram realizadas e estão em fase de finalização. $O$ foco deste artigo, portanto, é a análise do discurso institucional sobreo uso das redes sociais produzido pelos gestores dessas ferramentas, servidores dos parlamentos. A forma como a gestão dessas ferramentas é realizada, bem como os conceitos e opiniões expressas pelos servidores encarregados dessa tarefa, ajudam a explicar as escolhas e dilemas enfrentados pelas equipes e, consequentemente, iluminam quais são os reflexos disso nos conteúdos publicados.

Depois desta introdução, o segundo item traz um breve panorama teórico dos estudos relacionados ao tema. Na sequência, as informações colhidas nas entrevistas com os gestores são cotejadas com autores que analisam as práticas institucionais de parlamentos nas redes sociais sob dois aspectos: possibilidades e obstáculos ao seu uso. Ao final, propõe-se uma reflexão sobre a prática dos parlamentos estudados a partir dos conceitos de e-transparência e e-participação, eixos desta análise.

\section{Digitalização do Parlamento}

No espaço de mais de uma década, em vários países diversos autores se dedicaram a compreender as relações dos parlamentares com os cidadãos por meio das mídias sociais fora dos períodos eleitorais (WILLIAMSON, 2009; ARAÚJO; GONZÁLEZ, 2011; SAEBO, 2011; TÚÑEZ; SIXTO, 2011; VIANA; OLIVEIRA, 2011; BRAGA; CRUZ, 2012; CONTREIRAS, 2012; ALMEIDA, 2014; LARSSON; KALSNES, 2014; MARQUES; AQUINO; MIOLA, 2014A; 2014B; BARROSET AL., 2015; GEBER; SCHERER, 2015; NICOLÁS; BRAGA, 2015; TAVARES; QUIROGA, 2015; AMARAL, 2016; LARSSON, 2016; ALMEIDA, 2017; ARAÚJO; TRAVIESO-RODRÍGUEZ; SANTOS, 2017; COOK, 2017; LEV-ON; PORAT; LEHMAN-WILZIG, 2017; PESSONI; SANTOS, 2018; PEREIRA; SANTOS; BERNARDES, 2019; ALMEIDA ET AL., 2020). Em menor número, alguns pesquisadores também focalizaram o uso das mídias sociais pelas instituições parlamentares, em estudos comparativos entre parlamentos nacionais (PORTILLO; FERNANDEZ, 2013; GIRALDO-LUQUE ET AL., 2017) e subnacionais (MENDONÇA; PEREIRA, 2016; MUSTAFA; SHARIFOV, 2018; RODRÍGUEZANDRÉS; ÁLVAREZ-SABALEGUI, 2018).

Para além da prática institucional, o panorama político social também tem sofrido alterações por conta dos usos sociais da tecnologia. O processo de aquisição de informação política (MARGETTS, 2013, p.427), por exemplo, tem sido fortemente afetado pela Internet, especialmente com a proliferação dos sites de redes sociais. Democratização da disseminação da informação, criação de fontes alternativas, expansão de processos deliberativos, influência sobre o voto e incremento da participação política são outras mudanças observadas (MARGETTS, 2013, p.428-429). 
Defensora do conceito de Democracia expresso por Beetham e que inclui o controle popular e a igualdade política desse controle, Margetts afirma que a Internet pode facilitar as formas do cidadão conseguir informações, se engajar e influenciar as instituições democráticas (2013, p.431). Porém, ao contrário do que os pesquisadores esperavam no século XX, desigualdades de renda e educacionais sãoreforçadas no contex to digital, dificultando a igualdade no exercício do controle político.

Em relação à transparência, Zuccolotto e Teixeira destacam que ela é uma condição necessária "para que o povo possa exercer a interação com os representantes, controlá-los e, ao fim do ciclo de representação, exercer o poder negativo" (2019, p.13-14). Relacionado à divulgação de informações por parte dos governos para atores internos e externos, o conceito parte de três correntes de ideias precursoras: "o governo deve agir de acordo com regras previsíveis e estáveis, a comunicação deve ser franca e aberta com a sociedade e devem existir formas de tornar tanto a organização quanto a sociedade cognoscível” (ZUCCOLOTTO; TEIXEIRA, 2019, p.20). Eles acrescentam ainda que o desenvolvimento tecnológico das tecnologias de informação e comunicação e a melhora dos níveis de democracia no mundo provocaram a ampliação da importância do termo no século XX, levando governos a adotarem leis de abertura e transparência, tanto no âmbito nacional comono subnacional (ZUCCOLOTTO; TEIXEIRA, 2019, p.33), e instituições públicas a desenvolverem iniciativas para a transparência eletrônica, inicialmente, e posteriormente, digital - a e-transparência.

De certa forma, a e-transparência seria uma condição necessária para que os processos de e-participação dos cidadãos juntos às instâncias decisórias possam se realizar, isto é, para que os cidadãos possam efetivamente influenciar as decisões políticas. Assim, conforme a categorização proposta por Sampaio et al. (2019), a e-transparência estaria relacionada às categorias de 1. Monitoramento de contas, obras e políticas; 2. Dados abertos; 3. Acompanhamento dos representantes; e 4. Informação e educação para a cidadania, enquanto a e-participação relacionase com as atividades de 5. Expressão de reivindicação civil; 6. Participação; e 7. Deliberação. Importante frisar queno contex to contemporâneo, o "e" antes dos termos, que significa eletrônica, pode ser tranquilamente substituído por "digital".

Os conceitos de e-transparência, que implica uma visibilidade maior das informações sobre as instituições públicas e resulta em políticas de dados abertos, e de e-participação, atividades de expressão de interesses e opiniões populares sobre o Estado e influência popular sobre as decisões políticas, estão inseridos na reflexão de Margetts (2013) e de Sampaio et al.(2019). Mas como essas duas dimensões aparecem nos discursos mobilizados pelos gestores da prática digital das casas legislativas?

Leston-Bandeira (2007), em um estudo já clássico sobre a digitalização dos Parlamentos, levanta três funções básicas dos processos digitais que se conectamàs funções clássicas exercidas pelas casas legislativas nos regimes representativos: 
a) Criar novas possibilidades comunicativas junto a públicos diversos e promover a aproximação com o cidadão - REPRESENTAÇÃO E EDUCAÇÃO;

b) Disseminar informações de modo ágil e barato, promovendo transparência e controle público - LEGISLAÇÃO E FISCALIZAÇÃO;

c) Tornar os processos internos de gestão mais eficientes, ampliando eficácia e eficiência da burocracia - ORGANIZAÇÃO INTERNA.

A partir das funções parlamentares enumeradas por Leston-Bandeira, percebe-se que as preocupações com a tran sparência e disseminação das informações legislativas, como base para os processos de representação, educação e fiscalização, e a participação política dos cidadãos no processo decisório - que suporta a representação e a legislação - precisam também fazer parte do processo de digitalização dos Parlamentos. Caso contrário, a realização das funções parlamentares pode ser prejudicada.

Um exemplo de como essas duas preocupações podem ser traduzidas em iniciativas digitais é o Banco de Relacionamento com os cidadãos criado pela ALMG. A experiência foi citada pela Gerente de Relações Institucionais da assembleia mineira, Daniela Santiago Mendes Menezes, como uma tentativa de criar ações que despertem o interesse da sociedade sobre a Casa Legislativa. Por meio desse sistema, o cidadão customiza o seu acessoàs informações disponíveis nas diferentes plataformas digitais da Casa, ampliando seu leque de dados disponíveis sobre a instituição. Por exemplo, o cidadão pode dar o check-in na comissão e imediatamente começar a receber as diferentes informações produzidas pelos diferentes setores sobre aquele assunto específico, acompanhando as diferentes etapas do processo legislativo e as diferentes decisões tomadas dentro do Parlamento. É o que destaca a gestora:

\begin{abstract}
Temos muita relação com a sociedade civil organizada, o sistema serviu para a mpliar esse relacionamento com o cidadão, a pessoa física. Para viabilizar o relacionamento com o cidadão, ele é solicitado a autorizar e mudar essas autorizações por meio do portal, ou seja, ele mesmo controla as licenças para os serviços. A parte tecnológica já está feita e o banco permite que haja uma regularidade de entrega dos produtos informativos de forma customizada, por meio de uma conexãoentre os diferentes sistemas da Casa (MENEZES, 2018, sem paginação).
\end{abstract}

A explicação da gestora mostra que as casas legislativas estão encontrando necessidade de ampliar o seu contato com os cidadãos, para além dos integrantes de grupos de interesse e de pressão, usuários constantes dos novos sistemas digitais. Será que a estratégia pode contribuir para diminuir as disparidades relatadas por Margetts, especialmente entre grupos da sociedade civil organizada e os cidadãos dispersos socialmente, em relação ao poder de que dispõem para influenciar as decisões políticas? Como Menezes ressalta,

Acho que esse é o caminho para a Comunicação Pública. Lógico que esse cidadão já é interessado sobre política, tem clareza sobre os seus campos de interesse e já tem manejo da internet. Seria o que chamamos de um 'público 
quente', que já está mais próximo do Parlamento e da questão política (MENEZES, 2018, sem paginação).

A menção ao conceito de Comunicação Pública revela uma percepção da importância da publicidade e da visibilidade das decisões políticas para que a população possa, no mínimo, posicionar-se sobre elas, o que tem uma relação bastante estreita com a e-transparência e suas justificativas normativas, mencionadas anteriormente. Contudo, não parece que as iniciativas digitais sejam suficientes para acabar com as desigualdades sobre o controle popular, nos termos de Beenthame Margetts.

Em relação, especificamente, às redes sociais, Sunstein (2018) defende que elas tornam mais fácil para as pessoas obterem informações e comunicá-las aos outros, por conta de sua disseminação paraoutros grupos sociais. Segundoo autor, as redes são um trabalho em progresso, porque evoluem constantemente e há sempre novos entrantes, dentro de uma lógica colaborativa de produção de conteúdo.

Será que as mídias sociais, portanto, permitem às casas legislativas aprofundar esse contato com os cidadãos e ampliar a e-transparência? Será que por meio delas um cidadão que normalmente não está interessado nas ferramentas institucionais criadas pelos parlamentos pode entrar em contato com a instituição representativa e, através de sua participação, influenciar os rumos decisórios do Parlamento? O próximo item, especificamente, trata das possibilidades abertas pelo uso das redes sociais pelos Parlamentos a partir da visão da literatura e dos próprios gestores dessas ferramentas.

\section{Possibilidades das redes sociais para as assembleias}

Especificamente em relação ao Parlamento, Leston-Bandeira e Bender (2013) avaliam que mídias sociais têm potencial considerável para estimular a habilidade de instituições legislativas em promover o engajamento ${ }^{5}$ dos cidadãos, especialmente por atenderem às seguintes condições: 1) acesso direto aos cidadãos sem a mediação de atores externos; 2) acesso direto ao público jovem; 3) reação institucional mais rápida a fatos e eventos; 4) potencial de engajar o cidadão em conversações; 5) potencial de atingir públicos específicos; 6) potencial de participação política para os cidadãos (LESTON-BANDEIRA; BENDER, 2013, p.283).

Williamson (2013) também aproveita o conceito de boyd e Ellison de mídias sociais em sua análise das regras que devem nortear a adoção delas por parlamentos. Entre as vantagens do

\footnotetext{
${ }^{5} \mathrm{O}$ conceito de engajamento público usado aqui tem o sentido formulado por Leston-Bandeira (2014), com cinco etapas - não necessariamente sequenciais - do ponto de vista dos cidadãos: 1) acesso à informação, 2) desenvolvimento de compreensão sobre o parlamento, 3) percepção da importância da instituição e identificacão da relevância de suas atividades para a própria vida, 4) motivação para participação nos resultados do processo legislativo, e 5) possibilidade de intervenção e engajamento com parlamentares na discussão e decisão legislativa (LESTON-BANDEIRA, 2014). A participação, neste sentido, é apenas uma etapa do processo ou fluxo, que pode se iniciar em qualquer outra fase e seguir em diferentes direções. Ou seja, não há um caráter competitivo entre participação e representação, conforme realizada pelos parlamentos.
} 
uso das mídias sociais pelos parlamentos, estão exatamente a abertura de espaço para o diálogo; a aproximação do usuário do seu público; e a criação de credibilidade e confiança na instituição. Segundo ele, os objetivos das instituições legislativas nessas plataformas podem ser sintetizados em quatro pontos: 1) prover novas formas de comunicação e engajamento com o público; 2) possibilitar consultas à legislação; 3) disseminar recursos educativos; e 4) promover transparência.

O autor prossegue detalhando as demais funções que as mídias sociais podem cumprir para as instituições legislativas: estímulo a maior transparência; oportunidades para apoio a partidos minoritários ou grupos de pressão; distribuição viral; custo-benefício; melhor compreensão da opinião pública; monitoramento em tempo real; redução no tempo para obtenção da informação; inclusão como elemento central da estratégia de comunicação, disseminação e engajamento (WILLIAMSON, 2013).

Williamson destaca ainda que as redes sociais podem servir para monitorar tendências, conversas e sentimentos, algo que até então só poderia ser feito por meio de pesquisas de opinião, inacessíveis por seu custo à maior parte dos atores políticos. Em outros termos, as redes podem auxiliar as instituições a gerir as informações compartilhadas pelo público sobre o trabalho legislativo, intenção compartilhada pela equipe da ALESP, como informa Manuela Sá, Diretora de Redação do Departamento de Comunicação da assembleia de São Paulo.

\footnotetext{
Não conseguimos conversarcom essas pessoas, e isso seria muito bacana, até mesmo para obtermos sugestões de conteúdos que elas querem ver nas nossas redes. Foi por meio da sugestão de uma seguidora que começamos a colocar a agenda da Casa nos stories do Instagram. Ela nos disse que a forma como o site apresentava a informação não era de fácil visualização. Essas sugestões são muito bacanas, o nosso propósito é usar as redes como ferramentas de gestão das informações mesmo (SÁ, 2019, sem pa ginação).
}

Em certo sentido, para além da observação dos cidadãos sobre os representantes, as redes sociais também possibilitam que os atores políticos tenham acesso à opinião de parce las da sociedade, intensificando as duas direções da transparência vertical (ZUCCOLOTTO; TEIXEIRA, 2019, p. 40) e ampliando assim as possibilidades de accountability. A transparência tem relação, portanto, com os níveis de informação, identificação e compreensão do processo de engajamento (LESTON-BANDEIRA, 2014) e com a visibilidade da informação política.

Para aproveitar todo o potencial das redes sociais, Alaôr Messias Marques Júnior, Diretor de Planejamento e Coordenação da ALMG, ressalta, contudo, que é necessário um maior envolvimento da área parlamentar e dos deputados no uso dessas ferramentas. Segundo ele, há uma "tentativa de engajá-los nesse movimento de melhorar o contato da Casa com a sociedade, para convencê-los de que isso melhora o contato direto deles com a sociedade também". Complementa o autor: 
Acho que o nosso desafio é a aplicação de novas formas de participação que atendam às novas funções do Legislativo. A maioria dos nossos canais levam à formulação legislativa. São ferramentas para subsidiar a elaboração da lei, sugestões de projeto de lei, opinião sobre projetos em tramitação. Mas como podemos promover a participação no papel do Legislativo como AVALIADOR e FISCALIZADOR das políticas públicas? (MARQUES JÚNIOR, 2018, sem paginação).

Em relação à influência das redes sociais no panorama político, o estudo de Halpern et al. (2017) afirma que o Facebook afeta positivamente as crenças sobre as capacidades de ação coletiva dos grupos que se engajam na ferramenta. Segundoos autores, os segmentos que utilizam a mídia social como espaço deliberativo para encorajar a participação cívica acabam motivando os participantes a incrementarem suas ações na própria ferramenta. Esses indícios mostram o potencial da plataforma como meio para os movimentos sociais criarem oportunidades de engajamento cívico. Vitak et al. (2010) complementam mostrando que a interação entre os pares pode ser um estímulo mais poderoso ao engajamento em atividades políticas do que mensagens genéricas enviadas pelos próprios atores políticos.

Neste cenário, o uso das ferramentas digitais multiplica-se e requer maior dinamismo da parte dos atores políticos, especialmente aqueles que atuam diretamente nas redes de interlocução política. Ampliam-se, portanto, as estratégias de comunicação política que visam melhor e maior conexão entre representantes e eleitores, bem como uma ampliação da confiança nas instituições, com vistas a superar lacunas de accountability dos sistemas políticos.

As redes sociais também cumprem uma outra função: permitem que atores políticos e instituições se comuniquem diretamente com seus públicos, sem passar pelo crivo da mídia eletrônica. Obviamente, isso traz vantagens e desvantagens para as próprias instituições, como observa o profissional encarregado da produção de conteúdo para as redes sociais na Alerj, Daniel Tiriba:

As redes dão mais a lcance e permitem um trabalho diferenciado. A mídia tem
um filtro, não necessariamente ruim ou bom, mas as redes permitem que você
atinja quem está na cauda longa, pois aumentam a capacidade de falar com a
população que tem interesses específicos que não serão contemplados pela
mídia. As redes não vão substituir a mídia, mas complementá-la (TIRIBA,
2018, sem paginação).

Por outro lado, como ressaltam duas outras entrevistadas, também os deputados têm suas próprias redes, seus perfis e seus canais, não dependendo mais dos canais institucionais para se comunicarem com seus eleitores. Com as redes deles se amplia exponencialmente o nível de informação que é disseminado sobre a Casa Legislativa nas plataformas digitais, ainda que eles nem sempre mencionem os perfis oficiais das assembleias em suas postagens, como lembraram vários servidores. Entretanto, se não há mais o interesse particular de cada representante em ter espaço de divulgação nas mídias legislativas ou nos perfis institucionais, qual passa a ser o papel desses veículos? "Não seríamos um lugar de encontro entre o deputado azul e o vermelho?", 
questiona Fabíola Farage, gerente geral de Imprensa e Divulgação e gestora do Projeto Presença Digital da ALMG.

Ou, como aponta também Tiriba, a função da comunicação realizada pelos perfis tem como objetivo a transparência das ações legislativas para que o cidadão possa participar do processo:

Rea lizamos uma tarefa nobre e funda mental, não podemos fingir que algo não existe. Comunicação social de órgão público não é só melhorar a imagem da Casa, a função é fazer com que as pessoas saibam o que a contece aquidentro e como funciona o Legislativo. Obviamente, há outros meios de divulgação. Precisamos de mais a mor na política (TIRIBA, 2018, sem paginação).

Para alguns autores, as mídias sociais representam, na verdade, um impulso à personalização na comunicação política (BENNETT, 2012), pois colocam o foco nas políticas individuais, mais do que nas instituições (ENLI; SKOGERBO, 2013, p.757). Assim, aspectos personalizados e dialógicos podem contradizer as estratégias comunicacionais estruturais dos partidos e demais instituições, incluindo aí os parlamentos (2013, p.758). Como destacam Enli e Skogerbo (2013), aliás, a personalização é um dos traços da midiatização da política no início do século XXI, juntamente com a popularização da política e o fim do limite claro entre político e privado, público e pessoal. Afinal, as redes são, segundo os autores, espaços semi-públicos/semiprivados para autorrepresentação, ou seja, cumprimos papeis públicos e privados nelas (ENLI; SKOGERBO, 2013, p.759).

Cass Sunstein (2018, p.85) vai mais longe e diz que uma experiência cada vez mais personalizada para os usuários das redes é um sério problema para a democracia, um verdadeiro "pesadelo". O autor destaca, ainda, os três princípios de um sistema de comunicação em um ambiente democrático:

1) Cidadãos precisam ser expostos a materiais que não escolheriam sozinhos, com diferentes perspectivas daquelas que eles têm;

2) Muitos ou a maioria dos cidadãos deve ter um amplo espectro de experiências comuns;

3) Cidadãos precisam ter condições de distinguir entre o que é falso e verdadeiro e perceber manipulações (SUNSTEIN, 2018, p.85).

A perspectiva de Sunstein fornece uma justificativa normativa para o interesse público na manutenção dos perfis institucionais das casas legislativas nas redes. Contudo, para além da perspectiva política ou social que afirma a necessidade de espaços institucionais para o debate, qual seria a validade de se observar perfis e blogs mantidos pelos próprios atores políticos e instituições, se o mais interessante pode estar ocorrendo entre os cidadãos comuns nas plataformas privadas, em termos de debate? Para Wright (2011, p.249), são duas as razões: 1) porque o discurso político passa pelos atores institucionais antes de chegar ao cidadão comum, já que eles são formuladores desse discurso; e 2) porque alguém precisa ver como esses atores institucionais 
se integram ao panorama digital mais amplo nesses espaços institucionalizados.

$\mathrm{O}$ argumento de Wright é de que as pessoas usam várias tecnologias para discutir a política, ou seja, que o impacto da internet não pode ser determinado pelo estudo isolado de uma ferramenta (WRIGHT, 2011, p.254). Para o autor, além disso, a observação desses espaços de conversação política deve enfatizar a discussão, e não a deliberação, uma vez que o pessimismo com os resultados do processo deriva de um ideal que foi desenhado pelos teóricos e que não tem base empírica (2011, p.250-251).

Marques Júnior ressalta que há uma tentativa de trazer a participação para os canais institucionais das Casas Legislativas, por conta das questões de gerenciamento da informação, "enquanto a sociedade discute em outros espaços que nós nem conhecemos e nem aproveitamos", em uma referência explícita às redes sociais e aos perfis de outros atores sociais. Um ponto que também é motivo de preocupação para outros gestores está relacionado exatamente às bolhas informativas, que podem atrapalhar a transparênciae a visibilidade dasinformações sobre as casas legislativas, como lembra Tiriba:

A ferramenta é gratuita, é quase sem custo para a instituição, já que se usa a estrutura que existe para os outros veículos de comunicação. Mas a mensagem precisa chegar a todo mundo, não a penas à s pessoa s interessa da s na quilo, para fomentar a tolerância. (...) A formação de identidades é importante, mas e a bolha? E quando nos isolamos? O social subentende a coletividade, mas se criam guetos que entram em guerra. Se cria uma certa desilusão com as ferramentas, pois elas estão causando uma distensão social que é assustadora (TIRIBA, 2018, sem paginação).

De qualquer forma, como destaca José Geraldo Prado, diretor de Comunicação da ALMG, o engajamento digital não é a solução para todos os males que afligem as democracias representativas ou os parlamentos. Há muitos outros fatoresque importam para o estabelecimento da relação comunicativa entre representantes e representados:

\footnotetext{
Creio que não podemos nos entusiasmar em excesso com a participação virtual, até que se tenha mais clareza sobre isso, sobre o valor de cada voto virtual. Precisamos tratá-la como relativa, os números absolutos podem não significar tudo isso. Tecnologia + dinheiro + lobby mudam tudo nesse panorama. São questões que estão fora do nosso alcance resolver (PRADO, 2018, sem paginação).
}

Ainda que não possam resolver o panorama contextual de surgimento das red es sociais, as casas legislativas têm sido cada vez mais demandadas a fazer um uso público dessas ferramentas. Se elas encontram formas diversas de explorar o potencial das redes, como revelam alguns depoimentos, as divergências não são tantas assim, especialmente em relação às dificuldades relatadas. O próximo item discute com maior aprofundamento os obstáculos à realização dessa tarefa identificados pelos gestores. 


\title{
4 Obstáculos ao uso de redes sociais pelas assembleias
}

Leston-Bandeira (2007) reconhece que há vários obstáculos para a realização plena dos processos de digitalização dos Parlamentos de forma mais ampla, isto é, não apenas para o uso das redes sociais. As principais dificuldades apontadas pela autora repousam em quatro dimensões essenciais:

a. Organização administrativa - conflitos entre setores, paralisia decisória, fragmentação dos processos, resistência à inovação, falta de flexibilidade para mudanças;

b. Falta de recursos - materiais, estruturais ou humanos, planejamento inadequado;

c. Falta de vontade política - resistência dos representantes à participação cidadã, resistência à transparência, receio da fiscalização pública, disputa pelo controle dos processos, dificuldade de manejar o feedback social, necessidade de gestão da imagem;

d. Dificuldades dos cidadãos para participação - falta de interesse, dificuldades cognitivas e informacionais, falta de confiança nos espaços e arenas institucionais, exclusão digital.

Essas questões são pertinentes à prática e à reflexão que os gestores das ferramentas digitais nas assembleias legislativas desenvolvem, como destacam os servidores entrevistados para esta pesquisa ${ }^{6}$. Um dos pontos mencionados por todos elesdiz respeito aos recursos materiais e humanos necessários para a realização adequada das atividades relacionadas à digitalização dos processos comunicativos.

A falta de equipes dedicadas exclusivamente à produção de conteúdo para as redes (item B) é uma dificuldade ressaltada por Fabíola Farage, especialmente por conta da necessidade de respostas aos comentários e perguntas, argumento enfatizado por Griffith e Leston -Bandeira (2012). Na Alerj, a coordenadora do Núcleo de Marketing e Projetos Especiais, Tainah Vieira segue a mesma linha de raciocínio:

\begin{abstract}
Necessitaríamos de maior atenção para os comentários, de mais equipe para lidar com isso. Eu acho que os perfis nas redes funcionam como um SAC, por isso, devería mos responder os comentários sempre. Devería mos produzir ma is conteúdo especial para as redes, com gente que saiba produzir conteúdo para redes. Precisaríamos trabalhar de formas diferentes os conteúdos, fazer ma is campanhas, a companhar melhor o que outros órgãos estão fazendo (VIEIRA, 2018, sem paginação).
\end{abstract}

As dificuldades de pessoal para gestão das redes estão presentes de forma ainda mais acentuada nas assembleias de São Paulo e do Espírito Santo, que contam com equipes bastante modestas - um servidor e dois estagiários em ambas, ainda que somente na ALES o servidor atue exclusivamente nas redes - em relação às estruturas mais robustas de ALMG e ALERJ ${ }^{7}$. Na

\footnotetext{
${ }^{6}$ Para dar clareza ao argumento, mencionamos cada um dos itens identificados por Leston-Bandeira nos comentários feitos pelos gestores como item $\mathrm{A}$, item $\mathrm{B}$, etc.

${ }^{7}$ A ALMG conta com uma Gerência de Mídias Digitais, responsável pelo conteúdo das redes e do Portal, imagens para redes sociais e portal, e desenvolvimento de aplicações, especialmente conectadas ao desenvolvimento do Portal
} 
ALESP, Manuela Sá relata que apesar do Departamento de Comunicação ter 25 funcionários, apenas ela é jornalistae não há servidores dedicados exclusivamente à produção de conteúdo para as redes (item B). Ela destaca ainda a necessidade de treinamento e preparo dos profissionais para efetivamente realizarem as tarefas com qualidade (item A):

A dificuldade é que não há profissionais treinados para realizarem essas tarefas. Alguém precisa fazer um treinamento para conseguir usar as redes, é necessário que um servidor se dedique a essas tarefas. Além disso, há várias outras coisas que são feitas por esses profissionais, como as visitas monitoradas, a comunicação interna, várias outras funções (SÁ, 2019, sem paginação).

No Espírito Santo, o gestor de design e de mídias sociais da assembleia, Lucas Albani, também relata dificuldades similares. Por exemplo, o perfil da TV ALES no YouTube é usado como um canal de streaming para a emissora, porque a equipe não dispõe de recursos humanos e materiais para produzir conteúdos exclusivos para o canal (item B). Segundo ele, a situação está melhor nos últimos anos, mais ainda há questões que precisam ser estruturadas a partir da vontade política:

\begin{abstract}
As instituições públicas vêm caminhan do para melhorar, para dar mais a tenção aos usuários, mas ainda falta consciência da gestão sobre a importância da atividade. Hoje temos aquina ALES o a poio dos deputados, o presidente sabe da importância das redes, conseguimos uma estrutura básica para funcionar, mas precisaríamos de muito mais voz (ALBANI, 2019, sem pa ginação).
\end{abstract}

Nem sempre, contudo, a questão é simplesmente demandar mais pessoal ou dinheiro. Marques Júnior aponta que a dimensão organizacional (item A) precisa de melhorias "para um melhor suporte para a atuação finalística dos parlamentares", uma vez que é preciso falar com as entidades sociais e com o cidadão individualmente. Isso envolve, segundo ele, a exigência de "uma mudança da cultura interna, de posicionamento dos servidores", ou seja, implica alterações na dimensão interna da organização administrativa apontada por Leston-Bandeira (2007). O gestor complementa:

Há uma dificuldade estrutural de nos a daptarmos de modo razoávela essa nova composição de públicos e de debates. Precisamos conseguir redirecionar a capacidade da Casa para esse novo lugar, mas não conseguimos abrir mão de outras coisas que já fazemos (MARQUES JÚNIOR, 2018, sem paginação).

Coleman (2004) ressalta que o gerenciamento do tempo para lidar com as ferramentas digitais é um dos pontos que explicam a adoção ou não desses canais. Essa preocupação, que é crucial para os deputados como aponta a pesquisa britânica (COLEMAN, 2004, p.14), também

\footnotetext{
Mobile. Também produzem conteúdo para intranet. Ao todo, são cinco webdesigners, cinco jornalistas que produzem conteúdo, um gerente, dois estagiários de Publicidade e uma estagiária de Jornalismo. Na Alerj, o Núcleo de Marketing e Projetos Especiais tem uma coordenadora, um jornalista produtor de conteúdo e dois estagiários. Obviamente, as informações sobre as equipes são bastante dinâmicas, por conta das dimensões políticas às quais estão submetidos os servidores das casas legislativas. Por isso, pode haver alterações nesses números desde a coleta até a publicação deste estudo.
} 
preocupa os servidores das instituições políticas encarregados da gestão dessas ferramentas. A quantidade de mensagens que circula nas redes dificulta o gerenciamento da informação para que seja usada de forma adequada.

Além da enorme quantidade de dados para gerenciamento, outra dificuldade que os gestores enfrentam diz respeito à característica das redes sociais: são plataformas desenvolvidas e gerenciadas por empresas particulares, isto é, não estão sob o controle das instituições políticas e funcionam a partir de regras próprias, que não estão direcionadas à publicidade estatal, mas à sistematização e venda de dados sobre gostos e preferências dos usuários. Assim, a moderação feita pelos gestores das casas legislativas nem sempre consegue ser efetiva para promoção do debate, além de faltar vontade política para resolver algumas tensões com a opinião pública (item C). É o que ressalta o sub-diretor de Comunicação da Alerj, André Coelho (itens A, B e C):

\begin{abstract}
Em 2017, a crise financeira do Estado atingiu totalmente a Alerj. Recebemos muitos comentários negativos, e mais ainda com a prisão dos deputados logo em seguida. Chegamos a fazer posts pagos no Facebook quando tínhamos o contrato com a Agência de publicidade, mas com a crise nunca renovamos o contrato. Aconteceu tudo ao mesmo tempo, inclusive as mudanças no algoritmo do Facebook. Levamos muito pau (COELHO, 2018, sem paginação).
\end{abstract}

Daniel Tiriba, por sua vez, aborda a questão dos algoritmos para destacar a nec essidade da transparência e visibilidade das informações sobre o Parlamento para a realização das etapas de informação, compreensão e identificação do processo de engajamento:

\begin{abstract}
Estamos no meio do tiroteio, impulsionamento ajuda a chegar em quem tem mais interesse. Mas o Facebook é frustrante. É uma tarefa de luta contra a ferramenta. Você tem 40 mil seguidores, mas ele só entrega a postagem para $2 \%$ disso. Temos um desafio aí: como furar a bolha e o ódio para disseminara importância do Poder Legislativo, da diversidade de opiniões, do debate, exatamente para sair da bolha. Mostrar que a instituição é plural, que ela representa todos os deputados, que constituem uma massa heterogênea. Mostrar que o Poder Legislativo faz parte da vida das pessoas, com os serviços que pode prestar, especialmente de fiscalização do Executivo, com o Alô Alerj, para garantir a prestação dos serviços públicos pelo Estado (TIRIBA, 2018, sem paginação).
\end{abstract}

Os argumentos e exemplos dos gestores encontram apoio em estudos que analisam o funcionamento dos algoritmos ${ }^{8}$ nas redes sociais. Sastre et al. (2018) destacam a ação do que denominam de "filtro bolha", isto é, a atividade dos algoritmos como filtros no ambiente virtual. Essa ação faz os algoritmos atuarem como motores de previsão que in fluenciam e direcionam o acesso ao conteúdo a partir do perfil e hábitos de consumo do usuário, o que cria no indivíduo uma sensação de eficiência na busca ao restringir a pesquisa sobre o conteúdo, conforme o argumento de Pariser citado pelos autores (SASTRE et al., 2018, p.6).

\footnotetext{
${ }^{8}$ Algoritmo é um conjunto de regras que, aplicadas sistematicamente a alguns dados de entrada apropriados, resolvem um problema em um número finito de passos elementares, segundo a definição de Fanjul citada por Sastre et al. (2018, p.13).
} 
Dessa forma, os algoritmos influenciam os conceitos de qualidade e credibilidade da informação, pois interferem no sistema de acesso ao conteúdo (SASTRE et al., 2018, p.6). O senso comum passa a relacionar uma boa posição no motor de busca com uma informação credível, e a credibilidade deixa de ser da fonte original da informação para ser influenciada pelo responsável pelo compartilhamento da notícia (2018, p.7-8). Por esse mecanismo automatizado, o filtro bolha limita o acesso do u suário a informações favoráveis a um posicionamento, criando oportunidades para que o usuário acredite em fake news. Sunstein, por sua vez, chama as Fake News e as bolhas de opinião de "acidentes das redes sociais" que levam ao aumento da fragmentação, polarização e extremismo (SUSTEIN, 2018, p.84). Segundo o autor, a polarização que aumenta com as redes tornará cada vez mais difícil governar.

A questão da polarização política nas redes sociais não passa despercebida dos gestores, como argumenta José Geraldo Prado, ao mencionar a problemática:
A bolha digital se reproduz em outros ambientes, pois eles evitam as circunstâncias de embate. É um dos riscos que corremos com a internet. Temos que fomentar o debate entre os divergentes? (...) (PRADO, 2018, sem paginação).

Todos os servidores entrevistados revelam preocupação com a qualidade do debate que é travado nas redes, especialmente a partir de questões práticas como os problemas de pagamento para uso de funcionalidades das plataformas (item A), necessidade de impulsionamento das mensagens, falta de qualidade das contribuições do público, agressividade entre os usuários etc (item D). Como destaca Ana Carolina Utsch Terra, gerente de Mídias Digitais da ALMG, para que as postagens cheguem à população do interior do Estado, a assembleia precisa pagar, patrocinaros posts dentro da plataforma. Uma agência de publicidade orientou a equipe nesse sentido, mas o projeto não foi para frente por causa disso, por conta dos obstáculos ao uso de recursos públicos em publicidade (itens A e C). Por isso, as postagens sobre o programa "Viva Minas", que trata de festas locais representativas da cultura dos municípios, por exemplo, não aparecem para quem está nesses municípios, abrindo uma lacuna no contato com a população difícil de ser ultrapassada.

Outro ponto em conexão é a necessidade de monitoramento do conteúdo das redes para analisar as tendências de opinião expressas pelo público e, até mesmo, perceber quais são as necessidades informativas da população (item D). Além das dificuldades no desenvolvimento de expertise técnica para coleta e análise dos dados gerados pelas redes sociais, as casas legislativas enfrentam o desafio de falta de acesso a ferramentas gratuitas ou minimamente acessíveis do ponto de vista financeiro para realização da tarefa (itens B e C). Em 2019, por exemplo, a retirada do ar do Netvizz, aplicativo para coleta e análise de dados do Facebook, complicou ainda mais o monitoramento das redes, obrigando usuários organizacionais e institucionais a pagar pelo serviço para empresas especializadas nisso. Como explica Manuela Sá: 
O problema é que não temos o monitoramento desse material, não fazemos nada com os comentários que entram no "O que você acha?". Não temos as ferramentas para esse monitora mento ainda, mas o objetivo é ter. Quando são envia das perguntas, respondemos se conseguimos, os dema is comentários não respondemos. Muitas vezes eles comentam entre si, discutem, brigam, desabafam, para isso não respondemos. Obviamente, não conseguimos responder na velocidade que eu gostaria e que seria bacana. Além da falta de equipe, a falta de ferramentas de monitoramento das redes é um desafio (SÁ, 2019, sem paginação).

Obviamente, no caso das redes sociais, uma dificuldade adicional ao monitoramento é a quantidade ex trema de dados gerados por postagens e comentários dos usuários. Entretanto, como ressalta Gomes (2018), a questão não é apenas numérica ou de dimensão, mas da criação de uma inteligência computacional que possa coletar de forma automática e analisar esses dados, produzindo conhecimento a partir deles.

No caso da ALES, Albani revela que a licitação para compra de uma ferramentabrasileira de monitoramento já estava sendo finalizada no segundo semestre de 2019. Segundo ele, a grande vantagem das redes sociais em relação a outros canais de comunicação é a possibilidade de feedback quase instantâneo. Mas a análise desse retorno é um dos desafios, uma vez que a comunicação das assembleias não se pauta por critérios mercadológicos ou comerciais, conforme ele mesmo destaca:

\begin{abstract}
Temos desafios o tempo todo, especialmente porque a gente não tem meta de mensuração comercial, então como vamos saber se uma postagem deu certo? Só trabalha mos com conteúdo, prioriza mos o que o outro precisa saber, porque as pessoas esperam que a assembleia produza determinados tipos de informação. Não estamos aqui para lucrar, é uma lógica de comunicação pública mesmo, e ao contrário das redes socia is dos parlamentares, também não estamos aqui para melhorar a imagem deles para a próxima eleição (ALBANI, 2019, sem paginação).
\end{abstract}

Williamson (2013) alerta que a entrada no ambiente das redes sociais digitais oferece riscos à instituição parlamentar, além de questionamentos aos próprios representantes e servidores das casas legislativas. Os principais riscos mencionados pelo autor são: etiqueta e protocolos são diferentes das demais mídias; riscos que afetam a reputação se não for autêntico, honesto e transparente; necessidade de ser percebido como relevante pela audiência, não por si próprio; requer conteúdo cuidadosamente direcionado; potencial de sair rapidamente de controle; recrutamento é difícil de prever e não há garantia de diálogo produtivo; não é um atalho para eficácia comunicativa.

Soma-se a esses desafios a percepção dos gestores de que o momento político não é favorável aos parlamentos (itens C e D), como destaca Prado:

Estamos vivendo um momento de descrédito, descrença, crise da política e do parlamento. Se a crise é uma oportunidade, temos muitas agora, pois há mudanças o tempotodo. Perceber as oportunidades é o nosso desafio (PRADO, 2018, sem paginação). 
Partindo dos relatos e reflexões compartilhadas pelos gestores das assembleias legislativas, analisa-se, no próximo item, como os conceitos de transparência e participação são articulados no discurso sobre a prática comunicativa realizada por meio das redes.

\section{E-Transparência e E-Participação para quem?}

A partir do amplo conceito de Democracia Digital apresentado, Simon et al. definemuma tipologia de atividades que podem ser enquadradas no escopo dele. São elas: informar aos cidadãos, enquadrar as questões públicas, permitir aos cidadãos que forneçam informações, que compartilhem ideias, e que providenciem expertise técnica sobre as questões públicas (atividades que podemos enquadrar dentro do escopo da transparência), deliberar, permitir aos cidadãos que desenvolvam e avaliem propostas, permitir que eles tomem decisões e ainda que monitorem as ações públicas (em conexão com a participação) (SIMON et al., 2017, p.13).

Percebe-se que as atividades listadas fazem parte do arcabouço teórico da Democracia contemporânea, que parte da disseminação das informações para embasar as decisões cidadãs, por meio dos processos de transparência - a democracia liberal aponta o voto bem informado como única possibilidade de interferência do cidadão sobre o regime - até chegar na participação efetiva da população sobre as decisões políticas. Essa participação pode ser feita ao fornecer subsídios e expertise ao Estado, tomar parte na deliberação e nas decisões ou ainda avaliar e monitorar as ações efetivadas. No mesmo sentido, Gomes (2018) ressalta que os conceitos da etransparência e da e-participação por meio das ferramentas digitais fazem parte das preocupações de pesquisa daqueles que estudam as iniciativas, e tambémdas preocupações normativas daqueles que desenham as experiências e ferramentas.

Sobre a e-transparência, as pesquisas já realizadas sobre portais e sites dos parlamentos indicam que a divulgação das informações sobre o funcionamento institucional e político das casas legislativas já está consolidada nas ferramentas digitais (BRAGA, 2008; FARIA, 2012; BARROS ET AL. 2015; BARROS ET AL. 2016; BERNARDES; LESTON-BANDEIRA, 2016; MENDONÇA; PEREIRA, 2016; MITOZO, 2018). Da mesma forma, as redes sociais institucionais legislativas parecem ser usadas, primordialmente, para disseminação de informações sobre a agenda e o processo legislativo, o que inclui as opiniões dos parlamentares sobre diferentes assuntos (LESTON-BANDEIRA, 2016; GIRALDO-LUQUE et al., 2017; MUSTAFA; SHARIFOV, 2018; WORLD E-PARLIAMENT REPORT, 2018) e serve como exemplo de como a e-transparência é desenvolvida nos processos de digitalização. Como atesta a gestora da Alesp, as redes são, efetivamente, mais um canal de comunicação com a população, promovendo transparênciaativa (ZUCCOLOTTO; TEIXEIRA, 2019, p.48) e a maior visibilidade das informações sobre o Legislativo: 
eu quando entrei aqui dizia que precisava ser alfabetizada de novo. Então a intenção é mastigar esse conteúdo, torná-lo mais simples e direto para que o cidadão comum possa compreendê-lo, possa entender o que está sendo feito dentro da ALESP. Tentamos traduzir mesmo essa informação, de forma ma is simples e rápida para o cidadão.

As vantagens das redes sociais são fazer a informação chegar de forma mais simples às pessoas. A informação já está no Portale no Diário Oficial, mas lá ela tem uma linguagem muito técnica, muitas vezes inacessível para o cidadão comum. Nossa tentativa nas redes é simplificar a informação para o cidadão (SÁ, 2019, sem pa ginação).

Mas, para além de seu amplo potencial informativo para a e-transparência, como atestam as pesquisas e o uso cotidiano que os atores políticos fazem deles, os sites de redes sociais teriam alguma possibilidade de estimular a e-participação?

Para obter um resultado mais eficiente e eficaz das redes sociais, Williamson (2013) recomenda que sejam estabelecidos objetivos estratégicos para o uso da mídia social. Segundo o autor, as questões principais que precisam ser analisadas e definidas previamente pelas equipes, portanto, são:

1) Quem queremos engajar,

2) O que queremos que as pessoas façam,

3) Como pretendemos usar as contribuições,

4) Como iremos responder.

A perspectiva proposta pelo autor revela uma clara preocupação com o potencial dialógico dessas ferramentas e, portanto, com o retorno - seja informativo, seja opinativo - que a população pode dar aos representantes por meio delas. No caso da ALES, Albani revela que a preocupação em responder aos comentários e perguntas dos usuários é central para da gestão do perfil institucional:

Estimulamos os comentários, muitas vezes na legenda ou nas próprias imagens. Não ocultamos comentários de críticas, somente se forem de ódio, ofensivos ou agressivos. Além disso, respondemos a todos os comentários para mostrar para a pessoa que comentou que estamos vendo a opinião dela, que ela não está falando sozinha. Também tentamos fazer o atendimento e dúvidas e questões pelo inbox o mais rápido possível.

Fico praticamente $24 \mathrm{~h}$ olhando as redes, muitas vezes respondo de casa, a não ser que seja algo que necessite de alguma pesquisa para responder (ALBANI, 2019, sem paginação).

Porém, as dificuldades enfrentadas pelas equipes de criação desses canais de comunicação (MENDONÇA; PEREIRA, 2016) revelam que as considerações de LestonBandeira (2007,p.664) sobre o papel fundamental da burocracia no processo de digitalização dos parlamentos podem ainda não ter sido completamente compreendidas por gestores e parlamentares, desembocando em falta de vontade política para realizações dos processos de etransparência e e-participação por meio das redes sociais dos parlamentos.

Apesar do estudo de Enli e Skogerbo (2013) focar no uso das mídias sociais pelos 
candidatos ao legislativo durante campanhas eleitorais, algumas considerações podem se aplicar ao cenário mais amplo da comunicação política no período entre eleições. Assim, atores políticos usam os seus perfis de Facebook, Instagram ou Twitter, entre outros, com os objetivos de marketing e visibilidade; mobilização de eleitores e cidadãos; e como oportunidade de diálogo (ENLI; SKOGERBO, 2013). Se não cabe aos perfis institucionais das casas legislativas a realização de marketing eleitoral, a ampliação da visibilidade da instituição continua sendo um objetivo importante, assim como podem ser a mobilização dos cidadãos para a atuação política e o estabelecimento de um diálogo público entre a instituição e a sociedade. É o que confirma Célia Abend, diretora de Comunicação da Alerj:

Procuramos nos engajar em campanhas pelas redes, pois notamos que as pessoas estão cansadas da política tradicional. Quando o assunto envolve a sociedade, conseguimos capturá-los para a discussão, de forma mais positiva (ABEND, 2018, sem paginação).

Sem o estabelecimento de um diálogo ef etivo (e-participação) e sem a possibilidade de monitorar com qualidade os dados gerados pelas redes (e-transparência), como as casas legislativas podem atender aos interesses da população? É um questionamento que os próprios gestores estão realizando, como demonstra o depoimento de Albani:

\footnotetext{
Acho que precisamos perguntar o que as pessoas querem, para trazer esse debate para as redes. Sabemos que temos um retorno muito bom as sessões ao vivo no Facebook, muitos assessores da casa assistem, muita militância do interior que não tem acesso à TV Assembleia. Mas recebemos muito mais a poio do que debate, as pessoas não entram para perguntar, nem tirar dúvidas ou coisa s assim.

As leis mais interessantes, as coisas que têm a ver com o Estado, têm retorno mais legal. Não adianta muito colocar leis que não são relevantes. Aquilo que tem mais impacto no dia-a-dia das pessoas é o que tem mais retorno. Não adianta ficar falando da gente, se o tema não tem impacto, não terá retorno bacana sobre a Casa.

O perfil do público são adultos de 25 a 45/50 anos, geralmente do próprio estado e de estados mais próximos, igualmente divididos entre homens e mulheres. Creio que as pessoas mais envolvidas com política nesses estados também acessam nossos conteúdos (ALBANI, 2019, sem paginação).
}

Como esses perfis estão construindo uma relação dialógica com os cidadãos, se os gestores mal conseguemresponder aos comentários que entram? ComodestacamEnli e Skogerbo (2013), os perfis estão realmente se engajando em discussões políticas com os cidadãos? E em que medida aproveitam as oportunidades de diálogo com a população para melhor se conectar com ela, receber feedback nas questões políticas e engajar mais pessoas nas ações? O diálogo dentro das redes está sendo feito com os cidadãos comuns ou apenas com usuários engajados politicamente, isto é, a elite cultural ou política de cada estado? Sem o monitoramento adequado dos conteúdos e, principalmente, dos comentários às postagens submetidos pelos cidadãos, é muito difícil que as equipes tenham clareza sobre esses pontos.

Como ressaltam Crivellaro et al. (2014), as mídias sociais podem facilitar a emergência 
de movimentos sociais e o potencial para uma compreensão da política como complexa, contingente e contex tual, que estejaincluída nas preocupações cotidianas. O potencial de encontro e de mobilização propiciado pelas redes sociais pode levar à construção de coletivos reunidos por interesses ou demandas comuns, ou seja, as redes podem ajud ar na construção de laços sociais entre cidadãos dispersos. Nesse sentido, ler as postagens dos outros serve para vermos para onde as opiniões estão se inclinando e, assim, pode nos ajudar a manifestar opiniões divergentes ou convergentes. Fóruns de discus são e espaços de organização coletiva, os perfis e páginas nas redes sociais também podem servir para mostrar, segundo os autores, as formas de exclusão dos cidadãos no sistema político, na medida em que vozes que não eram ouvidas pelos canais tradicionais podem chegar aos representantes. Mas, como essas vozes podem ser efetivamente ouvidas por aqueles que detêm o poder de decisão?

É interessante perceber, por último, o fato de os perfis institucionais não se enquadrarem exatamente no fenômeno da personalização em sentido mais estrito. Em outros termos: que identidade os perfis institucionais constroem? Sendo instituições coletivas e deliberativas, altamente visíveis e controláveis publicamente, os parlamentos são o local privilegiado do conflito nas sociedades contemporâneas, pois são os fóruns onde as diferentes facções se expressam (LESTON-BANDEIRA, 2014, p.444). Instituições cheias de controvérsia e paradoxos, não dispõem de apenas umporta-voz para falarem seu nomee talvez sejam destinadas a não serem amados pela população, como ressalta Leston-Bandeira (2014, p.443). Como construir uma identidade com uma voz coerente nas redes, se eles abrigam governo e oposição, e todas as possíveis variações entre esses dois pólos? São questões ainda em aberto, que permitem que diferentes possibilidades para e-transparência e e-participação sejam experimentadas pelas casas legislativas nas redes.

\section{Conclusão}

A partir das questões levantadas pela literatura e pelos depoimentos, percebe-se que tanto os servidores quanto os teóricos estão preocupados com a garantia da qualidade do debate realizado nas redes sociais e seus efetivos resultados para o processo legislativo. Como dar transparência às decisões políticas tomadas dentro dos Legislativos? Como chegar de fato nas pessoas? Como fazer das redes, que são plataformas privadas, um lugar de participação pública? Como fazer com que as contribuições dos cidadãos sejam levadas em conta pelos representantes? Como deixar os cidadãos satisfeitos com o processo de engajamento pelas redes sociais? Ou as redes são apenas um espaço de desabafo do descontentamento com a política? Essas são questões que ainda permanecem sem respostas satisfatórias para a maioria dos analistas e dos próprios gestores dessas ferramentas.

Simon et al. (2017) recomendam um planejamento cuidadoso antes da criação ou execução das ferramentas. As etapas necessárias para isso segundo os autores, na linha do 
proposto por Williamson (2013), levam em conta quais são os objetivos do process o de engajamento, o que será feito com as colaborações, qual o suporte necessário dos decisores para ef etivar o processo, qual o processo necessário para o desenvolvimento completo da iniciativa, quais as ferramentas são mais adequadas para uma participação construtiva pelos usuários (SIMON et al., 2017, p.66). Os autores alertam ainda para o fato de que a digitalização não é a única resposta aos processos democráticos, pois o engajamento e a educação dos cidadãos podem ser alcançados pelos métodos tradicionais. Nesse sentido, destacam que:

Um exercício de participação só será bem-sucedido se as pessoas sentirem que há valor em sua contribuição - seja porque são capazes de influenciare moldar decisões, ou porque a proveitam algum tipo de motivação intrínseca, ou porque as questões em jogo são substantivas. Isso incentiva ma is pessoas a participar, e a fazê-lo de forma útil (SIMON et al, 2017, p.67). ${ }^{9}$

Em sua análise de variados exemplos de ferramentas de democracia digital, Simon et al. concluem que elas podem ser usadas para ampliar a qualidade, a legitimidade e a transparência do processo decisório (2017, p.87) e, em certa medida, para incluir nele os cidadãos que não fazem parte de organizações ou movimentos sociais (MENDONÇA; CUNHA, 2012, p.181). Mas para que tais iniciativas se tornem comuns, alguns desafios precisam ser pensados: desenvolver uma compreensão mais nuançada da participação, enfrentar a desigualdade digital, compreender as motivações da participação, equilibrar aspirações e realidade, aproveitar as novas tecnologias, entender o que funciona e quais são as limitações da democracia digital.

Além disso, os autores destacam algo que os servidores das assembleias já parecem ter compreendido: para que as iniciativas de democracia digital tenham impacto real no processo legislativo e nos resultados políticos, precisam ser abraçadas por aqueles que estão nas posições de poder, inclusive na oposição (SIMON et al., 2017, p.91), superando as dificuldades de vontade política apontadas por Leston-Bandeira(2007). E, consequentemente, criando condições para que a organização administrativa das casas legislativas se adapte ao cenário digital, superando a falta de recursos recorrentemente apontada pelos gestores e atendendo aos cidadãos em suas necessidades informativas sobre os parlamentos.

A partir desse apoio dos próprios parlamentares e de um certo nível de autonomia das equipes na execução das tarefas, inclusive para alcançarem os recursos técnicos e humanos que necessitam, parece que a digitalização se torna mais efetiva. Permanece, contudo, a dificuldade de integrar a voz política em atividades desenvolvidas tecnicamente, como ressalta LestonBandeira (2014). Especificamente em relação à produção de conteúdo para as redes sociais, a necessidade de os perfis institucionais permanecerem “neutros”, isto é, sem defender posições ou

\footnotetext{
${ }^{9}$ Tradução livre da autora para: "A participation exercise will only be successful if people feel that there is value in their contribution - either because they are able to influence and shape decisions, or because it taps into some sort of intrinsic motivation, or because the issues at stake are substantive. It encourages more people to participate, and to do so in a useful way." (SIMON et al., 2017, p.67).
} 
opiniões políticas sobre os temas que são abordados complica sobremaneira a atividade. Que é tratada nas redes, obviamente, de uma forma eminentemente opinativa. Em outros termos: qual a validade e o atrativo de um perfil que não opina sobre os assuntos que posta? Ressalte-se aqui que essa necessidade deriva da dificuldade de personalização de um perfil de uma instituição colegiada, como são os parlamentos.

A análise das práticas empíricas dos atores políticos, a partir dos depoimentos dos gestores das redes sociais nas assembleias legislativas, trouxe diversos elementos para o debate sobre as estratégias de comunicação das instituições políticas brasileiras e pistas importantes sobre os dilemas para o uso das ferramentas digitais em um cenário de desconexão e descrença na política. Percebe-se que, apesar de diferenças pontuais a partir das organizações internas dos parlamentos, os dilemas enfrentados pelos gestores das quatro casas le gislativas analisadas são bastante similares.

Ao que tudo indica, a preponderância informativa dos perfis - conectada ao desenvolvimento da e-transparência por meio das plataformas das mídias sociais - e suas estratégias de visibilidade impessoais podem complicar as escolhas discursivas dos gestores nessas ferramentas, diminuindo também o seu alcance junto ao público. De certa forma, os gestores apontam para a falta de vontade política direcionada para a e-participação e para o ef etivo diálogo com o cidadão - uma possibilidade aberta com as mídias sociais - como um empecilho ao aproveitamento mais intenso dessas ferramentas.

A partir desses pontos, o debate coletivo sobre as estratégias dos parlamentos para reconstruir a representação simbólica pode ser feito entre teóricos, pesquisadores, gestores e cidadãos. A e-transparência é condição necessária para a e-participação, mas, como demonstram os depoimentos, não é suficiente para que o processo se efetive. Pelo menos, não nos perfis das redes sociais mantidos pelas assembleias legislativas do Sudeste brasileiro.

\section{Referências}

AMARAL, Marcelo Santos. Congresso no Twitter: parlamentares e partidos políticos em 140 caracteres. 2016. Tese em [Administração]. Salvador: Universidade Federal da Bahia (UFBA).

ALMEIDA, Helga do Nascimento de. Análise dos usos das NTICs pelos parlamentares brasileiros: um estudo sobre o Facebook e o Twitter pelos deputadosfederais brasileiros em 2013. $3^{\circ}$ Encontro Nacional da ANPOCS. Trabalho apresentado no GT 22 - Mídia, política e eleições, de 27 a 31 de outubro de 2014, em Caxambu - MG. 2014.

ALMEIDA, Helga do Nascimento de. Representantes, representados e mídias sociais: mapeando o mecanismo de agendamento informacional. 2017. Tese em [Ciência Política]. Belo Horizonte: Universidade Federal de Minas Gerais (UFMG).

ALMEIDA, Helga do Nascimento de; PEREIRA, Marcus Abílio Gomes; FERREIRA, Maria Alice Silveira; QUINTÃO, Thales Torres. “Tamo junto?” Parlamentares e mídias sociais: uma tipologia dos padrões de atuação de deputados federais no Facebook. Revista Sociedade e Cultura. v. 23, n. 1, p.1-47, 2020. 
ARAÚJO, José Rúas; GONZÁLEZ, Borja Dapena. Los diputados del Parlamento Gallego em Facebook. REDMARKA UIMA, Universidad de A Coruña. Ano IV, n.7, p.77-106, 2011.

ARAÚJO, Ronaldo Ferreira; TRAVIESO-RODRÍGUEZ, Crispulo; SANTOS, Sarah Rubia de Oliveira. Comunicação e Participação Política no Facebook: análise dos comentários em páginas de parlamentares brasileiros. Informação \& Sociedade, v. 27, n. 2, p. 279-290, 2017.

BARROS, Antonio Teixeira de; BERNARDES, Cristiane Brum; RODRIGUES, Malena Rehbein. O Parlamento brasileiro e as novas mídias: balanço da experiência recente da Câmara dos Deputados. In: SATHLER, André; BRAGA, Ricardo de João. (orgs.). Legislativo Pós-1988: reflexões e perspectivas. Brasília: Câmara dos Deputados, Edições Câmara, 2015. P. 183-221.

BARROS, Antonio Teixeira de; BERNARDES, Cristiane Brum; RODRIGUES, Malena Rehbein. Brazilian Parliament and digital engagement. The Journal of Legislative Studies, Kingston upon Hull/UK, n. 22, p. 540-558, 2016.

BENNETT, W. Lance. The personalization of politics: Political Identity, Social Media, and Changing Patterns of Participation. The Annals of the American Academy of Political and Social Science, n. 644, p. 20-39, nov. 2012.

BERNARDES, Cristiane Brum; LESTON-BANDEIRA, Cristina. Information vs Engagement in parliamentary websites - a case study of Brazil and the UK. Rev. Sociol.Polit., Curitiba, v. 24, n. 59, p. 91-107, 2016.

boyd, Danah; ELLISON, Nicole. Social network sites: definition, history, and scholarship. Journal of Computer-mediated Communication, n. 13, p. 210-230, 2008.

BRAGA, Sérgio Soares. Podem as TICs auxiliar na institucionalização das Democracias? Um estudo sobre a informatização dos Órgãos legislativos na América do Sul e no Brasil. Brasília: Editora Plenarium, 2008.

BRAGA, Sérgio Soares. O Uso das Mídias Sociais é Um Bom Preditor do Sucesso Eleitoral dos Candidatos? Uma análise das campanhas on-line dos vereadores das capitais das regiões sul, sudeste, e nordeste do Brasil no pleito de outubro de 2012. Revista Política Hoje, Recife, v. 22, n. 2, p. 125-148, 2013.

BRAGA, Sérgio Soares.; CRUZ, Letícia Carina. Elites parlamentares e novas tecnologias: um estudo sobre o uso da internet pelos deputados estaduais brasileiros da $16^{\mathrm{a}}$ legislatura (20072011). Working papers/textos para discussão, 4. Curitiba: Observatório de Elites Políticas e Sociais do Brasil/Núcleo de Pesquisa em Sociologia Política Brasileira/Universidade Federal do Paraná, 2012.

CENTRO DE ESTUDOS AVANÇADOS EM DEMOCRACIA DIGITAL (Ceadd). Democracia digital no Brasil: uma prospeç̧ão das melhores iniciativas federais de 2015. Relatório de Pesquisa, 2015.

COOK, James M. Twitter Adoption and Activity in U.S. Legislatures: A 50-State Study. American Behavioral Scientist, v. 61, n.7, p. 724-740, 2017.

COLEMAN, Stephen. Connecting parliament to the public via the Internet: Two case studies of online consultations. Information, Communication \& Society, v. 7, n.1, p.1-17, 2004.

CONTREIRAS, Patrícia. Deputadas Parlamentares e Redes Sociais - O Mito das Redes como Facilitadoras de Proximidade entre os Políticos e os Cidadãos. Media \& Jornalismo, n.21, p.145$158,2012$.

CRIVELLARO, Clara; COMBER, Rob; BOWERS, John; WRIGHT, Peter C.; OLIVIER, Patrick. A pool of dreams: Facebook, politics and the emergence of a social movement. Proceedings of the SIGCHI. Conference on Human Factors in Computing Systems. Toronto, Ontario, Canada, p. 3573-3582, April 26 - May 01, 2014.

ENLI, Gunn Sara; SKOGERB Ø, Eli. Personalized Campaigns in Party-Centred Politics. Twitter and Facebook as arenas for political communication. Information, Communication \& Society, 
v.16, n.5, p.757-774, 2013.

FARIA, Cristiano Ferri Soares. O parlamento abertona era da internet: pode o povo colaborar com o Legislativo na elaboração das leis? Edições Câmara, Brasília, 2012.

GEBER, Sarah; SCHERER, Helmut. My voter, my party, and me. American and German parliamentarians on Facebook. Journal of Information Technology \& Politics, v. 12, n.4, p.360$377,2015$.

GIRALDO-LUQUE, Santiago; VILLEGAS-SIMÓN, Isabel; BUGS, Ricardo Carniel. ¿Cómo usan los parlamentos las redes sociales? Un estudio comparado y longitudinal aplicado a países de América y Europa (2010, 2015 y 2017). Revista Latina de Comunicación Social, n.72, p. 1.278-1.299, 2017.

GOMES, Wilson. A Democracia no Mundo Digital: história, problemas e temas. São Paulo: Edições SESC São Paulo, 2018.

GRIFFITH, Jeffrey; LESTON-BANDEIRA, Cristina. How are Parliaments Using New Media to Engage with Citizens? The Journal of Legislative Studies, n. 18, p.496-513, 2012.

HALPERN, Daniel; VALENZUELA, Sebastian; KATZ, James E. We Face, I Tweet: How Different Social Media Influence Political Participation through Collective and Intemal Efficacy. Journal of Computer-Mediated Communication, v. 22, p. 320-336, 2017.

Instituto Brasileiro de Geografia e Estatística. 2018. Projeções da População: Brasil e unidades da federação: 2018.2 Disponível em: https://biblioteca.ibge.gov.br/visualizacao/livros/liv101597.pdf . Acesso em: 25 out. 2019.

JENSEN, Jacob Linaa, Political participation online: the replacement and the mobilisation hypothesis revisited. Scandinavian Political Studies, v. 36, n. 4, p.347-364, 2013.

JÚLIO NETO, Gilson Arão. Desafios da comunicação pública face aos fluxos comunicacionais: Um estudo sobre a TV Assembleia/ES. XXIV Congresso de Ciências da Comunicação na Região Sudeste. Vitória/ES, 2019.

LARSSON, Anders Olaf. Online, all the time? A quantitative assessment of the permanent campaign on Facebook. New Media \& Society, v.18, n.2, p.274-292, 2016.

LARSSON, Anders Olaf; KALSNES, Bente. 'Of course we are on Facebook': use and non-use of social media among Swedish and Norwegian politicians. European Journal of Communication, v.29, n.6, p.653-667, 2014.

LEV-ON, Azi; PORAT, Chen Sabag-Ben; LEHMAN-WILZIG, Sam. A Facebook post is born: exploring the process of generating MP1s social media presence. The Journal of Legislative Studies, v.23, n.4. p.549-565, 2017.

LESTON-BANDEIRA, Cristina. The impact of the internet on parliaments: a Legislative Studies framework. Parliamentary Affairs, v. 60, n.4, p.655-674, 2007.

LESTON-BANDEIRA, Cristina. The pursuit of legitimacy as a key driver for public engagement: The European Parliament case. Parliamentary Affairs, v. 67, n. 2, p.437-457, 2014.

LESTON-BANDEIRA, Cristina. Why Symbolic Representation Frames Parliamentary Public Engagement. British Journal of Politics and International Relations, v. 18, n.2, p.498-516, 2016.

LESTON-BANDEIRA, Cristina; BENDER, David. How deeply are parliaments engaging on social media? Information Polity, n.18, p.281-297, 2013.

LUCINDA, Karine Aparecida. Comunicação Pública via Mídias Sociais: Estudo de caso da Assembleia Legislativa do Estado de Santa Catarina. [Monografia] Jornalismo. Florianópolis/SC: Universidade Federal de Santa Catarina (UFSC), 2016.

LUCINDA, Karine Aparecida; BERTASSO, Daiane. Comunicação Pública via Mídias Sociais: 
estudo de caso da Assembleia Legislativa do Estado de Santa Catarina. VII Congresso da Associação Brasileira de Pesquisadores em Comunicação e Política (VII COMPOLÍTICA. Universidade Federal do Rio Grande do Sul , Porto Alegre/RS, 10-12 de maio de 2017.

MARGETTS, Helen. The Internet and Democracy. In DUTTON, Williams H. (ed.) The Oxford Handbook of Internet Studies. Oxford/UK: Oxford University Press, 2013.

MARQUES; Francisco Paulo Jamil Almeida; AQUINO, Jakson Alves de; MIOLA, Edna. Deputados brasileiros no Twitter: um estudo quantitativo dos padrões de adoção e uso da ferramenta. Revista Brasileira de Ciência Política, Brasília, n. 14,p. 201-225, 2014a.

MARQUES; Francisco Paulo Jamil Almeida; AQUINO, Jakson Alves de; MIOLA, Edna. Parlamentares, representação política e redes sociais digitais: perfis de uso do Twitter na Câmara dos Deputados. Opinião Pública, Campinas, v.20, n.2, p.178-203, 2014 b.

MENDONÇA, Ricardo Fabrino; CUNHA, Eleonora Schettini Martins. Relatório Aprimoramento de Eventos da ALMG. Universidade Federal de Minas Gerais. Departamento de Ciência Política. Projeto "Aprimoramento de Eventos da ALMG”. Belo Horizonte, maio de 2012. $255 \mathrm{p}$.

MENDONÇA, Ricardo Fabrino; PEREIRA, Marcus Abílio. Dilemas na apropriação das TICs pela ALMG. Uma análise sobre a percepção dos gestores. In R. F. Mendonça, M. A. Pereira \& F. Filgueiras. (orgs.) Democracia digital. Publicidade, instituições e confronto político. Belo Horizonte: Editora UFMG, 2016. P.189-216.

MITOZO, Isabel Batista. E-Participação nos Parlamentos: desenvolvimento e uso de Iniciativas pela Câmara dos Deputados brasileira e pela House Of Commons britânica. Tese [Ciência Política]. Curitiba: Universidade Federal do Paraná, 2018.

MUSTAFA, Abdulsalam; SHARIFOV, Mahammad. Towards Enhancing Citizens Engagement: A Review of Parliamentary Websites in the 36 State Houses of Assembly in Nigeria. JeDE97-M, v. 10, n. 2, p. 97-111, 2018.

NICOLÁS, Maria Alejandra; BRAGA, Sérgio. As elites parlamentares sul-americanas e as NTICS: perfil sociopolítico e o uso da web por deputados e senadores do Brasil, Argentina, Chile, Paraguai, Uruguai e Venezuela. Revista NEP - Núcleo de estudos paranaenses da UFPR, v. 1, n.1, p. 61-82,2015.

PEREIRA, Marcus Abílio; SANTOS, Manoel Leonardo; BERNARDES, Cristiane Brum. Parlamentares conectados: um estudo sobre a utilização de tecnologias de informação e comunicação (TICs) na Câmara do Deputados (2014/2018). In: Anais do $2^{\mathbf{0}}$ Congresso do INCT.DD. Universidade Federal da Bahia. Salvador/BA, 3 e 4 de outubro de 2019b. P.1-44.

PESSONI, Arquimedes; SANTOS, Rita de Cássia Donato dos. A presença social dos Deputados Federais do Grande ABC no Facebook. Comunicação \& Sociedade, São Bernardo do Campo, v. 40, n. 2, p. 83-111, maio/ago. 2018.

PORTILLO, José Romero; FERNÁNDEZ, Manuel Mena. Parlamentos en Twitter. Análisis de los contenidos y la interactividad en @Congreso_Es y @HouseofCommons. Revista Comunicação Midiática, v.8, n.2, p. 232-259, mai./ago. 2013.

RODRÍGUEZ-ANDRÉS; ÁLVAREZ-SABALEGUI. Presencia y Actividad de los Parlamentos Autonómicos en las Redes Sociales: Pocos Avances em el Fomento de la Participación Ciudadana. El profesional de la información, v. 27, n. 5, p. 994-1003, 2018.

SAMPAIO, Rafael Cardoso; BRAGA, Sérgio; CARLOMAGNO, Marcio Cunha; MARIOTO, Djiovanni Jonas França; ALISON, Murilo Brum; SILVA, Tiago Philippini Ferreira Borges da. Estado da arte da democracia digital no Brasil: oferta e sobrevivência das iniciativas (1999-2016). Rev. Serv. Público, Brasília, v. 70, n. 4, p. 693-734, out/dez 2019.

SAEBO, Oystein. Understanding Twitter Use among Parliament Representatives: a Genre Analysis. In: TAMBOURIS, E.; MACINTOSH, A.; BRUIJIN, H. Third IFIP WG 8.5 
International Conference, Eletronic Participation. $1^{\circ}$ de setembro, 2011.

SASTRE, Angelo; OLIVEIRA, Claudia Silene Pereira de; BELDA, Francisco Rolfsen. A influência do "filtro bolha" na difusão de Fake News nas mídias sociais: reflexões sobre as mudanças nos algoritmos do Facebook. Revista GEMInIS, São Carlos, UFSCar, v. 9, n. 1, p.417, jan. / abr. 2018.

SIMON, Julie; BASS, Theo; BOELMAN, Victoria; MULGAN, Geoff. Digital Democracy. The tools transforming political engagement. UK: Nesta, February 2017.99 p.

SUNSTEIN, Cass. Is Social Media Good or Bad for Democracy? SUR 27, v.15, n.27, p. 83-89, 2018.

TAVARES, Daniel Nardin; QUIROGA, Tiago. O reforço do "homemcordial" nas conexões entre senadores e cidadãos nas redes sociais online. Revista do Instituto de Estudos Brasileiros, n.60, p. 110-128, 2015.

TÚÑEZ, Miguel; SIXTO, José. Social networks, politics and commitment 2.0: Spanish MPs on Facebook. Revista Latina de Comunicación Social, vol.66, p.210-234, 2011.

VIANA, David Henrique de Moura; OLIVEIRA, Bernardina Maria Juvenal Freire de. Redes Sociais e Política: Twitters dos vereadores de João Pessoa/PB. SimSocial - Simpósio em Tecnologias Digitais e Sociabilidade. Mídias Sociais, Saberes e Representações Salvador - 13 e 14 de outubro de 2011.

VITAK, Jessica; ZUBE, Paul; SMOCK, Andrew; CARR, Caleb T.; ELLISON, Nicole; LAMPE, Cliff. It's Complicated: Facebook Users' Political Participation in the 2008 Election. Cyberpsychology, Behavior, and Social Networking, v. 0, n. 0, 2010.

WRIGHT, Scott. Politics as usual? Revolution, normalization and a new agenda for online deliberation. New Media \& Society, v. 14, n.2, p.244-261, 2011.

WILLIAMSON, Andy. MPs Online: connecting with constituents. London: Hansard Society, 2009.

WILliamSON, A. Social Media Guidelines for Parliaments. Geneva, Switzerland, InterParliamentary Union, 2013.

WORLD E-PARLIAMENT REPORT. Genebra: União Inter-Parlamentar, 2018.

ZUCCOLOTTO, Robson; TEIXEIRA, Marco Antônio Carvalho. Transparência: aspectos conceituais e avanços no contexto brasileiro. Brasília: Enap, 2019.

\section{Entrevistas}

ABEND, Célia. Redes Sociais das Assembleias Legislativas. Diretora de Comunicação da Alerj. Conversa informal telefônica em 03/09/2018.

ALBANI, Lucas. Redes Sociais das Assembleias Legislativas. Publicitário, Gestor de design e de mídias sociais da ALES. Entrevista por vídeo do Whatsapp em 25/09/2019.

COELHO, André. Redes Sociais das Assembleias Legislativas. Sub-diretor de Comunicação da Alerj. Entrevista por vídeo do Whatsapp em 12/11/2018.

FARAGE, Fabíola. Redes Sociais das Assembleias Legislativas. Gerente geral de Imprensa e Divulgação e gestora do Projeto Presença Digital da ALMG. Entrevista presencial em 15/08/2018.

MARQUES JÚNIOR, Alaôr Messias. Redes Sociais das Assembleias Legislativas. Diretor de Planejamento e Coordenação da ALMG. Entrevista presencial em 16/10/2018.

MENEZES, Daniela Santiago Mendes. Redes Sociais das Assembleias Legislativas. Gerente de Relações Institucionais da ALMG. Entrevista presencial em 14/11/2018.

PRADO, José Geraldo. Redes Sociais das Assembleias Legislativas. Diretor de Comunicação 
da ALMG. Entrevista por Skype em 22/10/2018.

SÁ, Manuela. Redes Sociais das Assembleias Legislativas. Diretora de Redação do Departamento de Comunicação da ALESP. Entrevista por vídeo do Whatsapp em 24/10/2019.

TERRA, Ana Carolina Utsch. Redes Sociais das Assembleias Legislativas. Gerente de Mídias Digitais da ALMG. Entrevista presencial em 16/10/2018.

TIRIBA, Daniel. Redes Sociais das Assembleias Legislativas. Jornalista e designer encarregado da produção de conteúdo para as redes sociais na Alerj. Entrevista presencial em 28/09/2018.

VIEIRA, Tainah. Redes Sociais das Assembleias Legislativas. Coordenadora do Núcleo de Marketing e Projetos Especiais da Alerj. Entrevista presencial em 28/09/2018.

Artigo recebido em: 2020-07-14

Artigo reapresentado em: 2020-09-23

Artigo aceito para publicação em: 2020-09-28 